\title{
SPONTANEOUS ANTERIOR DISLOCATION OF AN INTUMESCENT CATARACT FOLLOWED BY A SUCCESSFUL REMOVAL*
}

\author{
BY \\ P. V. RYCROFT \\ London
}

IT is fortunate that an ophthalmic surgeon is seldom called upon to remove an intumescent mature cataract from the anterior chamber as an emergency procedure. The literature yields meagre information on cases of this nature, though posterior dislocation of the lens has received the attention of many writers.

Bickerton (1897) described two cases:

A 65-year-old woman had the lens removed from the anterior chamber 17 days after dislocation, by a vectis introduced through a corneal incision. In this case some aqueous could be released, but although the wounds healed, there was no perception of light in the eye after operation.

A 66-year-old man had a left cataract extraction in 1891, a preliminary iridectomy of the right eye being performed at the same time. In March, 1897, the right lens dislocated into the anterior chamber, and the eye became stony hard with perception of light only. A corneal incision was made through which the cortex of the lens fluid was removed, and a visual acuity of $6 / 36$ was attained after 81 days.

Bickerton also quoted a further case:

A 28-year-old man had congenital subluxation of both lenses which were clear without cataract. The history began with amaurosis fugax in one eye, and Eserine drops were instilled to counter one of these attacks, but later the sight failed to recover; the eye was red, the tension raised, and a clear lens filled the anterior chamber. At this time the results of extracting such lenses were considered unsatisfactory; it was decided to couch the lens into the vitreous. The pupil was dilated and aqueous evacuated by corneal section; the lens was pressed into the vitreous by a spatula in the anterior chamber. 3 years later the visual acuity was $6 / 5$ with $+10 \mathrm{D}$ sph., $+0 \cdot 75 \mathrm{D}$ cyl.

Other treatment recorded by Keeling (1900) included needling and scoop extraction. Jschreyt (1901) recorded six cases which came to enucleation.

Steijn (1925) reported an unusual case in which injury not only dislocated the lens, but also retroverted it in the anterior chamber; this eye was enucleated. A photograph of the histological specimen demonstrates that, as in the case to be reported below, there was no swelling or oedema of the corneal stroma.

More recently the subject has received brief mention in papers on dislocated lenses in general, which were classified as spontaneous, traumatic, or congenital in origin. In theory all lenses in the anterior chamber should be relatively easy to remove (Cashell, 1959); in practice, it depends upon how much of the anterior chamber is filled by the lens. For instance, in the author's case, the anterior lens capsule lay immediately behind the corneal endothelium, and the iris was so retroflexed and retroverted as to be scarcely visible, the entire anterior chamber being filled by the lens. In such a case, a Graefe knife or keratome incision is clearly useless if the lens is to be extracted within its capsule. 


\section{Case Report}

A man aged 45 years has a normal right eye with visual acuity $6 / 5$.

The left eye was normal until 1940 when there was contusion due to a training wound from a sabre butt. In 1951 this eye became "pink" and irritable, and in 1952 a blow caused a "black" eye. Subsequently, the vision became increasingly blurred, and a diagnosis of secondary cataract was made. From 1954-57 the vision deteriorated until in 1960 a mature cataract with accurate perception of light was recorded. The cataract was soft and white, with cells present on the posterior corneal surface; there was a flare, but no circulating cells in the anterior chamber, and the iris was atrophic. The intra-ocular pressure was raised, with no register on the Schiötz tonometer, and there was also $10^{\circ}$ of divergence. Diamox and miotics were prescribed.

The patient did not attend again until 3 years later, a month after spasmodic pain had developed over the forehead and left eye. While shaving at 7.45 a.m. on November 26, he noted that his eye looked normal, and 15 minutes later he saw in the mirror that his eye had become "covered with an elephant-grey disc, extending over the whole of the coloured part of the eye". During the next hour the pain gradually worsened, and 2 hours later it was "unbearable".

Examination.-A divergent, chemotic, engorged red eye was seen with wide dilatation of the episcleral and limbal vessels, showing apparent proptosis. On clinical inspection the cornea was transparent, and this was a unique state of affairs in a stony hard eye. Slit-lamp examination showed oedema of the epithelium with bullae, but no stromal or endothelial involvement.

There was no aqueous in the anterior chamber, which was entirely filled with cataractous intumescent lens: the iris was retroverted and showed only as a small pigmented rim. The patient was in pain, nauseated, and sweating profusely.

Medical Treatment.-Sedatives and $500 \mathrm{mg}$. Diamox were given orally at once and were followed by a further $500 \mathrm{mg}$. Diamox intramuscularly. Analgesic tablets, codeine, and aspirin were given, and preparation was made for immediate surgical removal of the lens, as there was no change in the intra-ocular pressure. Intensive miotics were instilled, gutt. Eserine 0.5 per cent. and Pilocarpine 4 per cent., every 10 minutes.

Surgical Treatment.-A routine gas, oxygen, and fluothane anaesthetic was administered. No intravenous urea, sucrose, or Diamox was used. $1.5 \mathrm{ml}$. Lignocaine 2 per cent. was given as a retrobulbar injection, and the eye was exposed with lid sutures and a superior rectus suture.

A Fleiringa's ring was stitched just in front of the equator in all four quadrants and a 4-mm. limbus-based conjunctival flap was turned down; copious bleeding was controlled with adrenaline 1:000, eye drops, and light cautery. The flap was dissected to the limbus with Tooke's knife, and extended $180^{\circ}$ around the upper half of the cornea. The intra-ocular pressure was checked again; the eye was stony hard with very little improvement from the retrobulbar injection or the general anaesthetic.

Using a Bard-Parker knife with a No. 15 blade, a half-thickness scleral section was cut just behind the limbus, and a pre-placed Maclean-type suture was inserted at 12 o'clock.

In order to produce a graduated lowering of the intra-ocular pressure, the incision at 11 o'clock was deepened to a width of $3 \mathrm{~mm}$. until a knuckle of iris was seen to prolapse into it. A broadbased peripheral iridectomy was performed, and some aqueous was lost with consequent lowering of tension, until vitreous prolapsed into the wound and plugged it.

An iris repositor was then passed backwards through the iridectomy, dislodging and rupturing the vitreous face; this resulted in a free flow of aqueous and a little vitreous. The intra-ocular pressure then became controllable, and the section was completed with scissors. It was noted that there seemed to be hypersecretion of aqueous, and advantage was taken of this to express the lens while the tension was slightly raised. The capsule was seized in Arruga's forceps, and the lens was removed. After removal, the capsule was broken, and milky lens fluid escaped: no nucleus was present. The pupil responded well to the miotics and contracted rapidly, with multiple petechial bleeding from its anterior surface.

Five buried Barraquer virgin silk sutures were used to close the section, and air was injected into the anterior chamber. Although the vitreous was broken through the iridectomy, the pupillary anterior vitreous face remained concave after the air injection, and a faint red reflex was noted. 
Progress. -24 hours later at the time of the first dressing the eye was still red and suffused, although more comfortable. The section was closed and striate keratitis was present; there was a 3-4 mm. hyphaema, but an air bubble was present in the anterior chamber which was fully reformed. No red reflex was present. The patient made an uneventful convalescence.

Result. -3 months later, the eye had settled, and the visual acuity was $6 / 9$ and N6, with +10 $\mathrm{D}$ sph., $+4 \mathrm{D}$ cyl., axis $180^{\circ}$. The intra-ocular pressure with the Goldmann applanation tonometer was $20 \mathrm{~mm}$. Hg. The eye was white, the cornea and anterior chamber clear, and the iris miosed, central, and circular, with the iridectomy clearly seen. The anterior vitreous face appeared intact and flat with some irido-vitreal synechiae. Gonioscopy revealed vitreous partially blocking the iridectomy, and the upper half of the angle of anterior chamber closed by peripheral anterior synechiae. The lower half of the angle was wide open, with some pigmentation of the trabeculae. The vitreous had multiple small blood clots inferiorly, but was clear axially.

There was only a small central cup of the optic disc despite the high pressure to which it had been subjected for 3 to 4 years. The visual field showed a marked nasal and upper temporal loss to within $10^{\circ}$ of fixation. No oedema of the macula was present.

\section{Discussion}

Perhaps the most striking feature of this patient's eye was the absence of oedema of the cornea, with an ocular tension which could only be described as stony hard: clinical evidence of the need for aqueous in the anterior chamber to render the cornea oedematous. Nevertheless, epithelial oedema was present and could be attributed to local limbal and conjunctival engorgement.

Apart from the absence of corneal oedema, this case resembled one of malignant glaucoma. The aqueous appeared to have pocketed behind the lens, and was not mixed with the vitreous. Moreover, the dislocation of the lens made possible an anterior approach, without resorting to posterior sclerotomy (Kirby, 1950) and its attendant complications. A sudden reduction in intra-ocular pressure might have resulted in the lens falling into the vitreous, and the pre-operative miotics would have made extraction extremely difficult. As it was, they undoubtedly prevented vitreous presentation into the section after removal of the lens in conjunction with the use of Fleiringa's ring, which was also essential to the success of the operation.

The advantage of a peripheral iridectomy with a wide basal portion, over a broad or complete iridectomy was two-fold: it enabled a controlled loss of aqueous and vitreous, while retaining the sphincter pupillae to effect miosis after the extraction.

Secondary glaucoma is nearly always a sequel of anterior dislocation; Hegner (1915) said that fourteen of a series of fifteen cases of traumatic and spontaneous anterior dislocation resulted in immediate glaucoma.

There seem to be two aetiological factors: mechanical obstruction of the filtration angle, and hypersecretion. Duke-Elder (1940) suggested "a circulatory derangement and stasis excited by neurovascular reflexes set up by mechanical irritation of the ciliary body". My observations lead to the conclusion that this irritation causes hypersecretion of aqueous, and that a combination of increased blood flow and hypersecretion causes a secondary glaucoma which may persist for some days even when the lens is removed.

In the case reported above the eye was congested to the point of engorgement, and the iris ecchymoses and anterior vitreous haemorrhage which occurred immediately after removal of the lens did not come from either the section or the iridectomy. 
Another unusual feature of this eye was that, despite at least 3 years of consistently high intra-ocular pressure, the optic disc showed only central cupping and minimal optic atrophy, which could have passed inspection as physiological. Yet the visual field was grossly reduced to within $10^{\circ}$ above and nasal to the fixation point, extending on the temporal side to $60^{\circ}$, inferiorly to $60^{\circ}$, and infero-nasally to $40^{\circ}$. The peripheral field was taken with the eye corrected using a 2/330 white target.

This case demonstrates that a normal healthy eye can withstand a high intra-ocular pressure for long periods without developing pathological cupping and optic atrophy, whereas an eye with chronic simple glaucoma shows signs of pathology earlier though subjected to less pressure. It would support the view that chronic simple (wide angle) glaucoma is not confined to a disease of the outflow channels, but implies involvement of the whole eye.

The complication of corneal dystrophy due to contact of lens capsule and endothelium (Burk, 1912; Wagenhäuser, 1913) was not present in this case. The lens was probably not in direct contact with the cornea for long enough to enable this to occur.

It was found that the Smith expression method extracted the lens easily once the section was complete.

An intracapsular extraction was considered essential to avoid a chronic irritable eye with the possibility of intractable glaucoma and lens induced uveitis. If the lens had been smaller, and had not filled the entire anterior chamber, vectis or spoon extraction would have been the method of choice (Kirby, 1950; Spaeth, 1948).

\section{Summary}

The successful removal of a dislocated intumescent mature cataract from the anterior chamber is reported and the method compared with previous techniques recorded in the literature.

I wish to record my thanks to Mr. C. A. G. Cook for permission to publish this case, and for his advice in the preparation of this paper.

\section{REFERENCES}

Bickerton, T. H. (1897). Ophthal. Rev., 16, 222.

BURK, A. (1912). v. Graefes Arch. Ophthal., 83, 114.

CASHELl, G. T. W. (1959). Trans. ophthal. Soc. N.Z., 12, 76.

Duke-Elder, S. (1940). "Text-book of Ophthalmology”, vol. 3, p. 3508 . Kimpton, London.

HeGNer, C. A. (1915). Beitr. Augenheilk., 9, 707.

JSCHREYT, G. (1901). Arch. Augenheilk., 42, 281.

Keeling, G. (1900). Ophthal. Rev., 19, 21.

KIRBY, D. B. (1950). "The Surgery of Cataract”, p. 486. Lippincott, Philadelphia.

SPaEth, E. B. (1948). “Principles and Practice of Ophthalmic Surgery”, p. 701. Kimpton, London.

SteIJn, J. S. (1925). Brit. J. Ophthal., 9, 20.

WAGENhäUSER, F. (1913). Klin. Mbl. Augenheilk., 51, (ii), 619.

\section{POSTSCRIPT}

The visual acuity 11 months after the operation is $6 / 6$ and N5 with an aphakic correction (6/4 with a contact lens, and partial stereopsis). The eye is divergent under cover only, and is cosmetically straight. It is white and quiet without further treatment, and the intra-ocular pressure is $14 \mathrm{~mm}$. $\mathrm{Hg}$ (applanation tonometer).

There is a definite increase in the pallor of the left optic disc, but little change in the degree of cupping. The visual field still shows almost complete nasal loss, but has improved temporally. 